THURSDAY, DECEMBER 17,1874

\section{THE TRANSIT OF VENUS}

$\Upsilon^{\mathrm{T}}$ is not too early to congratulate the world of science upon a grand triumph. The telegrams which have of late been flowing in almost incessantly from all parts of the Northern Hemisphere-now from far Japan and from Sibcria, recording the success of French, Russian, and American parties; and now from America, giving fuller details regarding the doings of the latter-leave no doubt whatcver that the weather has been better at the northern stations than might have been expected, seeing that the observations have been made in the winter half of the year.

Nor has the Northern Hemisphere been the only one to give us news. We already know of success at Melbourne and Hobart Town, at which place was an American party similarly equipped to those at Wladiwostok in Asiatic Russia, and at Nagasaki ; and Prof. Newcomb has already telegraphed to the Times that the eighty photographs taken by the American method at these places, combined with the I 3 taken at Hobart Town, are sufficient to give us a value of the solar parallax with a probable error of perhaps one-fortieth of a second of arc. This gives a foretaste of what photography is likely to do for us in this and the coming Transit of 1882 .

Before we proceed to detail the observations at the various stations, it will be well to re-state the various ways in which a Transit of Venus may be observed. This we will do almost in the words employed in a former article.

We have the utilisation of a Transit-

(a) By the determination of times of contact at different stations, combined with a knowledge of the longitudes of those stations.

(b) By the detemination of the least distances between the centres of the sun and $V^{\top}$ enus during the Transit, observed from different stations.

This last determination "may be made by-

(I) What is called Halley's method; or, if we wish that the world should forget a great work accomplished by a former great Astronomer Royal, we may term this the "mcthod of durations."

(2) By the Photographic method; or,

(3) By the Heliometric method.

Premising that the first method of determination $(a)$ was devised by Delisle, we have now our nomenclature sufficiently complete for present purposes, and we may begin with the stations at which this method can be best employed. Of these we have four groups: Accelerated Ingress, Sandwich Islands; Retarded Ingress, Kerguelen's Land, Heard or Macdonald Island, Mauritius, Bourbon, and Rodriguez; Accelerated Egress, Campbell Island, Emerald Island, Auckland Island, Royal Company's Island, and New Zealand; Retarded Egress stations in Western Russia, Persia, and Egypt.

Of these groups the northern ones can be used for Delisle's method solely, as only Ingress or Egress is seen ; Ingress in the Sandwich Island group, Egress in the Western Asiatic group. But the southern groups may be used for all methods.

For the methods we have grouped under $(b)$, stations in
Eastern and Southern Asia, combined with those in the Southern seas which we have already named, and stations between them, such as Melbourne and Adelaide, may be employed.

From the Sandwich Islands, Kerguelen's Land, Heard Island, Mauritius, Bourbon, and Rodriguez we have of course not yet heard ; we consequently know nothing of Delislean observations of Ingress.

Of observations of Accelerated Egress on this method we know nothing, but with regard to Retarded Egress we know that the English and Russian parties in Egypt have been wonderfully successful. At Teheran, a second class Russian station, but better adapted than Egypt for applying the Delislean method, the observations were a perfect success. At Ispahan, a German party obtained nineteen good photographs; but north of this, in the most favourable point of all, the Russian parties at Ormsk, Astrachan, and in all that region, there was complete failure.

From the English party several telegrams have been received since our last number appeared : a long one by the Times, and several shorter ones by the Astronomer Royal. These we give :-

"Cairo, Dec. 9.-The Transit of Venus was observed in all its phases by the astronomers of the Government Expedition in Egypt this morning, at the Central Station at Mokattam Heights. It was observed by Captain Orde and Mr. F. M. Newton at Suez, and by Mr. Hunter at Thebes. It was photographed by Captain Abney, and observed by Dr. Auwers and Prof. Dollen, also by Colonel Campbell and others. During the last three days the weather has been very bad, and this morning the telescopes in Cairo and Suez were directed to the eastern quarter of a sky clouded over, showing, however, a few breaks, which gave hope. Glimpses through the clouds exhibited Venus as a distinct black spot on the sun, but no opportunity was given for a micrometer measurement for nearly half an hour after sunrise; then a few chances were given through the openings in the clouds. A decided openings sccurred of a very hoperul character about ten ininutes before contact, and after one more cloud, which passed over two or three minutes only before the critical epoch, the observation of internal contact was made satisfactorily at every station in Egypt, and the photoheliograph has done its work well. The sky was quite clear for the measurement of cusps and any observations that could be made of external contact. The astrono. mers are satisfied with their observations. The phases are declared in Cairo to have so closely resembled those shown by Sir George Airy's model at Greenwich that it was hard to divest the mind of the idea that it was only model practice again. The Khedive has taken a warm interest in the work, and guarded the Mokattam station from intrusion by cavalry pickets. By means of the telegraph line he put up to Mokattam Heights, interchanges of telegraph time signals have been made between that station and Greenwich, Suez, and Thebes. This expedition has now, therefore, nearly completed its work, and in a few days will probably break up."

\section{Capt. Ord Brown, R.A. (Mokattam), Dec. 9 :-}

"The egress of Venus was observed at Mokattam this morning. There has been much bad weather and anxiety. All well now. Contact seen through very slight haze with [the] Lee [Equatorial] at about $13 \mathrm{~h} .25 \mathrm{~m}$. $25 \mathrm{~s}$. sidereal, and with De la Rue I3h. 22m. 2 Is. (Observe in the Greenwich book of observation with the model; my egress is always after other observers, except Mr. Gill's.) Clouds spoilt much double image work, but many limbs 
and cusps were taken. The phases closely resemble those of the model, except a line of light round the planet's edge, which appeared with strong sun just after the above contacts. It perplexed me and made me lose my best cusps. When I found that it continued two minutes and that it would be so indefinitely, I turned to cusps. I have exchanged bad telegraph signals twice with Thebes, and good ones three times with Suez.Mokattam Country, lat. $59^{\circ} 58^{\prime} \mathrm{I}^{\prime \prime} 4^{\prime \prime}$ "

\section{Mr. Hunter (Suez) :-}

"Sky cleared partly a few minutes before contact. Contact satisfactorily observed, and a considerable number of micrometer measurements made."

\section{Capt. Abney (Thebes) :-}

"Beautiful morning. Sun rather shaky at first, nice and sharp at time of contact, and good observations, though differing slightly in time. Sun pictures good. The fifty photographs in Janssen's slides include internal contact; external contact not taken. No black drop apparent in photographs after careful examination."

This, then, is all we know at present, or are likely to know for some little time, of the work done at purely Delistean stations. We now come to the stations at which the various methods of determining the least distance betwcen the centres of the sun and Venus during the Transit, observed from different stations, are applicable.

And we may clear the ground by referring to the news from the southern stations first. From Hobart Town has come the best news in a telegram to the Tines:-

"Prof. Harkness, of the American Transit Expedition at Hobart Town, reports, although the weather was bad, observations were particularly successful; II3 photographs were taken during the passage over the sun's disc."

We had previously heard of success from Melboune and Adelaide; but these stations are not so well situated as Hobart. Town, and it is doubtful if all the resources of a first-class fixed observatory, possessed by Mr. Ellery at Mclbourne, will make up for his comparatively poor position.

We now come to that region where, in fact, the whole intcrest of the Transit has centred during the past week : to Asia and the adjacent Japanese Archipelago, neglected in the English arrangements even after the Board of Visitors of the Greenwich Observatory had very clearly indicated their opinion of the original official programme, by insisting upon the employment of the "method of curations" in the Southern Hemisphere. But, fortunately for the credit of English science, an English possessionIndia-has something to say in the Asiatic work. On the representation of Col. Tennant (who has done so much for astronomical science by his observations in India) of the importance of a station in the northern part of that country-a represcntation which was at once warmly received by the Viceroy-the Home Government at once look the matter up, and the result has been that a firstclass observatory was erected at Roorkee. This was the Asiatic station from which news (which we chronicled last week) was first received.

But Northern and Eastern Asia was thickly studded with Russian, American, and French parties. In the Russian territory, Nertchinsk, Orianda, Charbarovka, Kiachta, Tschita, Port-Possiet, Wladiwostok, and many other places that we might name, were strongly occupied, and the wealth of results, whether in photography or heliometric measures, has been marvellous. One of these places-Wladiwostok-was occupied by an American as well as a Russian party. Herr Struve's telegrams to the Times regarding the observations at these places are as follows :-

"Wladiuestok.-Transit of Venus observed at both contacts, numerous chords and distances of the two limbs were measured.

"Port-Possiet.-Much clouds and mist; two interior contacts observed, and thirty-eight photographs taken.

"Charbarovka.-First two contacts and some chords observed.

"Tschita.-Contacts observed, and four series of measures with heliometer.

"Orindd.-Satisfactory observation of last two contacts.

"Nerlchinsh.-Three contacts observed, and two diameters and twenty distances of the planet measured with heliometer:

"Teheran.-Full success of observations.

"Thebes.-Splendid weather; very important observations.

"Kiachta.-Much cloud; got only eight photographs.

"Naratow-Clouds; complete failure.

"Possict.-Photographs satisfactory after development, though taken through mist."

The work done by the American party at Wladiwostok, as stated in a Reuter telegram in the papers on the IIth, was as follows :-

"Copenhagen, Dec. 9.--Prof. Hall telegraphs from Wladiwostok to-day, at 1o A.M., that the observations of the Transit of Venus made at that place by the American party under his direction have not been very successful, on account of the hazy and cloudy weather. The first and second contacts were observed, and thirteen photographs were taken."

In Japan there were French parties under Dr. Janssen at Nagasaki and Kobe, an American party also at Nagasaki, and Russian and Austrian parties at Yokohama.

The telegrams giving the account of Janssen's work we must transcribe as they were received.

"Nagasari, Dec. 9.-M. Dumas, Secretary Académie des Sciences and Minister Instruction, Paris.-Transit observed and contacts obtained. Fine telescopic imagres. No ligament. Venus seen over sun's corona. Photographs and plaques. Cloudy at intervals. Two members of our mission have made observations with success at Kobe."

"Transit observed at Nagasaki and Kobe. Interior contact, no ligament. Photographs revealed several clouds during transit. Venus seen over corona before contact. Gives demonstration of the existence of the coronal atmosphere."

The American party at Nagasaki has recorded its work in the following terms:-

"Day cloudy, but obtained second contact well-two observers; first and third contacts through clouds, and doubtful ; 150 micrometric measures of cusps, separation of limbs, and diameter of Venus; thirty-one meridian transits both limbs, Sun and Venus ; eighteen micrometric measures for difference of declination of limbs at meridian. About sixty good photographs. Ends threatening rain. Telegraph difference of longitude with Wladiwostok in November. All well." 
The following is a copy of another telegram to the New York Herala:-

"Wladiwostok, Sibcria, Dcc. 9 (ro.1o M.E.).-Prof. Hall reports much haze and cloud at Wladiwostok. First and second contact of Venus observed, and thirteen photographs taken near middie of transit. A calm bay, with tempcrature $34^{\circ}$; instruments and photographic apparatus working fincly. All the American party worlsing well."

The Russian and Austrian parties give no details ; thcy only announce their success.

There is now a certainty that in the Southern Hemisphere the eastern stations will be more strongly occupied than the western ones. The Americans were foiled in their gallant attempt to occupy the Crozets, because they had not time to wait for weather moderate enough for them to land their instruments. The party has therefore gone on to Campbell Island, where they will already find a French party. It is difficult to restrain one's pen when we think of the combination of want of a true appreciation of the conditions of the problem, and want of that old spirit which used to make us take up posts of difficulty, which has prevented England being represented here. A successful Polar Expedition will scarcely wipe away the national disgrace which is ours in consequence of official action in this matter, and the French and Americans may well be proud of the position they now occupy.

The Times thus relates the French landing on Campbell Island :-

"A letter has been received to-day (Dec. II), dated Campbell Island, Oct. 4, from the chicf of the French Expedition stationed there. This had been carried to Bourbon by the ship which had transported the expedition to Campbell Island, and which left it to wait at Bourbon until the time came for fetching the astronomers away. The first idea was to keep this ship off the coast of Campbell Island in order that the observers might live on board; after struggling three days against horrible weather they at last landed on the island, and they soon perceived that it was impossible to keep the ship off the shore, which was without shelter and exposed to terrible gusts of wind, so that it ran the greatest risk of being lost. The members of the expedition, seeing that if the ship were to go down they were exposed to very scrious danger-for they would be abandoned on an uninhabited island without means of communication, while everybody would think they still had the ship at their disposal-decided to unload the ship and establish themselves in the island and to send away the vessel, which would come and fetch them immediately after the observation of the phenomenon. This project was carried out. The observers began by organising temporary shelter, and then they built sheds to protect the instruments, the necessary utensils, and the provisions. The process of unloading was very long and troublesome, because the expedition, which has many members, had brought provisions for one year. While exploring the island they found nearly in the middle of the island a vessel which a hurricane had thrown there, and they were thinking of utilising the wreck, either by splitting it up or by placing themselves inside it, for protection against wind and weathcr. But two or three days afterwards another hurricane blew the ship out to sea, and they saw it no more. They were then obliged to do the best with all they had brought with them, for they were living in hourly dread of sharing the fate of the wreck.

"It is thought that since the 4th of October, the date on which the ship left for Bourbon, up to the moment of the triansit, the expedition will have completed its organisation, its observatories, and have been able to fulfil its mission. As soon as the ship reaches a telegraphic station, the expedition will hasten to communicate particulars to the Institute of France. Nothing is known, of course, as to the exact pericd when these communications will be received. The particulars relative to the difficulties of this expedition and the dangers to which it is exposed have becn received here with all the more interest that it was feared only two days ago that the Campbell Island station would not be organised in such a war as to make the observations under favourable conditions. It is still feared the weather may not have been favourable, and that so much fatigue and effort may not have been rewarded with the magnificent result it deserves."

It will be secn not only that a large number of observations have been made bearing on the main point, but that many side issues of great interest are raised. Dr. Janssen's observations have decidedly been amongst the most remarkable, not only with regard to the absence of the ligament, but as touching the visibility of Venus on the coronal atmosphere. Any detailed reference to these and many other points we must, lrowever, leave for a subsequent article. We have been anxious in the present one to put our readers in possession of the results of the observations, so far as we at present know them, in the most authentic and intelligible form.

\section{CHAPPELL'S "HISTORY OF MUSYC"}

The History of Music. Vol. I. From the Earlies: Records to the Fall of the Roman Empire. $B y$ William Chappell, F.S.A. (London: Chappell and Co., 1874 .)

N USIC is now being cultivated in a much more 1 earnest and thorough manner than heretofore, not only as a practical art, but as a matter of theoretical and historical interest, as is evidenced by the late formation of a "Society for the study of the Art and Science of Music," the object of which is to encourage musical studies of a higher character than those comprised in ordinary musical training. Hence, as the early history of music is one of the most interesting as well as one of the most obscure topics connected with the art, an authoritative new investigation like that before us is of real value.

Mr. Chappell, who has had much to do during his life with practical music, brolghit out some years ago a "History of the Ballad Literature and Popular Music of the Okden Time," a book which has become now of standard authority. on such matters. It seems that the eminent historian Mr. Grote suggested to him that he would do well to carry his inquiries further back, and to attempt to unravel the state of music among the Grecks. $\mathrm{H}$ is account of his progress is worth extracting. He says :-

"Mr. Grote's enthusiasm for the Greeks somewhat exceeded mine; and, although my recollection of the language was fresher than now, I did not suppose that, even if I should succeed, a knowledge of Greek art and science would greatly advance those of the moderns; therefore I received the proposal rather lukewarmly. But when favoured with the twelfth and last volume of the 'History of Greece,' with an inscription from the illustrious author, in deference to his long antecedent recommendation I took the first step forward, by buying the works of the Greek writers upon music.

"I had taken note of the odd uses of Greek words in manuscripts of the Middle Ages written in Latin; there- 